\title{
REVITALISASI DESAIN INTERIOR MUSEUM KEBANGKITAN NASIONAL JAKARTA
}

\author{
Tunjung Atmadi SP \\ Program Studi Desain Interior, Fakultas Desain dan Seni Kreatif \\ Universitas Mercu Buana Jakarta
}

\begin{abstract}
The existence of the Museum in general has not been able to optimally meet the needs of the community as a means of education and quality recreation. Ministry of Education and Culture (Kemdikbud) since 2011 has rolled out the Revitalization program of the Museum as an effort to improve the quality of the museum in serving the community and make the museum as a "need" to visit.

Revitalization at the Museum of National Awakening encompasses the physical appearance of the museum made interesting, by arranging the interior, exterior, and rehabilitation of other supporting facilities. The method applied in this research is qualitative method, perform analysis based on case study data with the theory used.

The result of this museum revitalization as a means of public learning, but also must be able to support the development of science. As an educational and academic function: the museum serves as a vehicle for education, a means of sharing knowledge and should be a center of study or a center of educational studies.
\end{abstract}

Keywords: Revitalization, public learning, study center.

\section{PENDAHULUAN}

Salah satu pendidikan dalam proses pembelajaran di tingkat sekolah dasar dan menengah tidak dapat dilepaskan dari museum, karena misi dari salah satu pendidikan adalah "Menanamkan pendidikan nilai, moral, etika dan sikap berbudi luhur serta bertaqwa kepada Tuhan Yang Maha Esa kepada siswa agar mereka dapat menjadi Warga negara yang baik, serta mampu memecahkan masalah-masalah sosial yang dihadapinya dalam kehidupan sehari-hari berdasarkan Pancasila dan UUD 1945". Misi pendidikan tersebut salah satunya dapat dicapai melalui kegiatan edukasi di museum, karena menurut Hunter (1988), tujuan pendidikan dengan pendekatan warisan budaya adalah untuk memperkuat pengertian siswa tentang konsep dan hasil seni, kecerdasan dalam bidang teknologi, serta kontribusi perbedaan kelompok sosial ekonomi pria dan wanita. (Konsepsi hakekat hidup).

Sebagai suatu institusi yang menyajikan berbagai hasil karya dan cipta serta karsa manusia sepanjang zaman, Museum merupakan tempat yang tepat sebagai sumber pembelajaran; karena melalui benda yang dipamerkannya, pengunjung dapat belajar tentang nilai dan perhatian serta kehidupan generasi pendahulu sebagai bekal di masa kini dan gambaran untuk kehidupan di masa mendatang. Sehingga tujuan dari pendidikan , yakni mendidik siswa untuk menjadi warga negara yang baik yang mampu melestarikan lingkungan dan budaya bangsa dapat terwujud. (Konsepsi hakekat lingkungan alam). Berbagai museum yang berdiri megah, mempunyai koleksi lengkap dan dipelihara dengan biaya yang tidak sedikit, kurang mendapatkan perhatian dari masyarakat. Persepsi masyarakat terhadap museum, hingga kini, masih jauh dari harapan. Artinya: sedikit sekali orang yang tahu dan mau memahami bahwa museum bermanfaat bagi dunia pendidikan dan rekreasi. Mereka umumnya memandang museum tidak lebih dari gudang tempat 
penyimpanan barang tua dengan suasana ruang interior yang menyeramkan. (Konsepsi hakekat lingkungan sosial).

Kenyataan ini memperlihatkan bahwa masyarakat yang membutuhkan museum relatif masih sedikit. Hal ini dapat kita saksikan dari minimnya jumlah pengunjung museum, baik secara perorangan maupun rombongan/kelompok. Selain itu, kebanyakan pengunjung museum yang berkunjung ke museum-museum yang ada di Indonesia, umumnya sebagian terbesar karena tugas sekolah, dan hanya sedikit yang datang karena ingin tahu atau keinginan sendiri. Kondisi ini jauh berbeda dengan keadaan di negara-negara maju, di mana kunjungan ke museum sudah menjadi suatu kebutuhan, terutama bagi siswa, karena merupakan bagian integral dari proses pembelajaran.(Konsepsi hakekat waktu).

Revitalisasi Museum merupakan upaya untuk meningkatkan kualitas museum dalam melayani masyarakat sesuai dengan fungsi museum. Pada pelaksanaannya, revitalisasi ini mengacu pada tiga pilar kebijakan permuseuman, yaitu mencerdaskan bangsa, memperkuat kepribadian bangsa, ketahanan nasional dan wawasan nusantara. Revitalisasi Museum terdiri atas enam aspek, yaitu fisik, manajemen, jejaring, program, kebijakan, dan pencitraan.

Salah satu sasaran program revitalisasi museum ini adalah penataan kembali penyajian koleksi pada ruang tata pamer. Membuat suatu Konsep Penataan Ruang Pameran Tetap di dalam museum bukan pekerjaan mudah, Karena menata ruang pameran tetap berarti melakukan penataan interior ruang dalam lengkap dengan koleksi museum beserta keseluruhan alat kelengkapan pendukungnya. Secara konsep ruang, penataan ruang pamer tetap tidak lepas dari desain interior di dalam museum terutama desain ruang publik beserta ruang fasilitas penunjangnya. Desain interior museum tidak dapat dipisahkan dengan penataan eksterior museum. Desain interior dan eksterior erat kaitannya dengan bangunan museum itu sendiri, (dalam lingkup pekerjaan rehabilitasi fisik bangunan museum). Konsep dasar desain interior ruang pameran tetap harus mengacu pada pertimbangan konservasi, keselamatan dan pengamanan benda koleksi pamer, dan kenyamanan pengunjung.

Untuk menyusun konsep rancangan atau desain interior ruang pameran tetap, ada 'kemutlakan' konsep yang harus dilakukan sebelumnya yaitu:

1. Adanya tema pameran tetap.

2. Adanya Alur cerita (story line).

3. Adanya Konsep penyajian pameran, dalam bentuk model yang dipilih oleh masingmasing museum.

4. Adanya Story board.

5. Matriks ruang pameran tetap yang memperlihatkan pembagian ruang-ruang bagi penempatan benda koleksi pamer dan panil informasi.

Komponen dalam penataaan ruang pameran tetap, yang harus menjadi konsep penting adalah harmonisasi antar komponen ruang yaitu lantai, dinding dan plafon. Selain variabel yang harus diperhatikan adalah pola, bahan, dan skema warna yang akan digunakan.

Seperti telah disampaikan dalam paparan diatas, salah satu program revitalisasi museum adalah renovasi ruang pamer tetap museum. Dalam hal ini jelas bahwa museum akan melibatkan pihak lain dalam membantu proses pembangunannya. Untuk itu manajemen museum dan kurator museum dituntut untuk memahami identitas museum dan barang koleksi agar mampu menjelaskan juga memberikan wawasan kepada pihak lain tentang desain interior ruang pamer tetap sekaligus konsep penyajian benda koleksi yang akan di pamerkan. Pada gilirannya museum diharapkan dapat menjadi tempat yang dirasakan sebagai kebutuhan masyarakat untuk dikunjung, sekaliguas sebagai sumber pembelajaran pendidikan bagi anak-anak sekolah maupun masyarakat umum. 


\section{TINJAUAN PUSTAKA}

Museum pada umumnya dikenal dengan sebuah gedung atau bangunan yang menyimpan koleksi benda-benda warisan budaya yang bernilai luhur yang dianggap patut disimpan. Dalam sejarah perkembangan museum mengalami perubahan-perubahan yang bersifat perubahan fungsi museum yang awalnya Kemudian berkembang dan bertambah dengan fungsi pemeliharaaan, pengawetan, penyajian atau pameran, dan akhirnya fungsi ini semakin bertambah. Dengan perkembangan museum muncul berbagai teori tentang pengertian museum. Beberapa pengertian museum:

Museum adalah Sebuah lembaga yang bersifat tetap, tidak mencari keuntungan, melayani masyarakat dan pengembangannya terbuka untuk umum, yang memperoleh, merawat, menghubungkan dan memamerkan, untuk tujuan pendidikan, penelitian dan kesenangan, barang-barang pembuktian manusia dan lingkungannya. (International Council of Museum)

Museum adalah lembaga, tempat penyimpanan, perawatan, pengamanan, dan pemanfaatan benda-benda bukti materiil hasil budaya manusia serta alam dan lingkungannya guna menunjang upaya perlindungan dan pelestarian kekayaan budaya bangsa. (Peraturan Pemerintah No. 19 Tahun 1995 Pasal 1 ayat (1))

Museum adalah tempat untuk mengumpulkan, menyimpan, merawat melestarikan, mengkaji, mengkomunikasikan bukti material hasil budaya manusia, alam dan lingkungannya. (Amir Sutaarga,1995:1). Adapun Peraturan Pemerintah No. 19 tahun 1995 tentang Pemeliharaan dan Pemanfaatan Benda Cagar Budaya di Museum, mendefinisikan museum sebagai lembaga, tempat penyimpanan, perawatan, pengamanan dan pemanfaatan benda-benda bukti material hasil budaya manusia serta alam dan lingkungannya guna menunjang upaya perlindungan dan pelestarian kekayaan budaya bangsa.

Museum sebagai pusat penelitian, museum berfungsi sebagai salah satu jaringan informasi ilmu pengetahuan. Museum sebagai salah satu lembaga pendidikan di luar sekolah formal. Artinya museum sebagai lembaga pendidikan berguna untuk penelitian bagi kepentingan pengunjung (G.D. Van Wager, 1990).

Menurut Francis D.K. Ching (2002:46) dalam Bentuk, Ruang dan Tatanan mengatakan bahwa desain interior adalah perencanaan tata letak dan perancangan ruang dalam di dalam bangunan. Keadaan fisiknya memenuhi kebutuhan dasar kita akan naungan dan perlindungan, memenuhi bentuk aktivitas dan memenuhi aspirasi kita dan mengekspresikan gagasan yang menyertai tindakan kita. Di samping itu sebuah desain interior juga mempengaruhi pandangan, suasana hati serta kepribadian kita.

Dari beberapa pengertian tentang museum diatas dapat disimpulkan bahwa museum adalah suatu lembaga yang berupa bangunan atau tempat yang berfungsi sebagai tempat mengumpulkan, menyimpan, merawat melestarikan, mengkaji, mengkomunikasikan bukti material hasil budaya manusia, alam dan lingkungannya, yang bermanfaat bagi kehidupan sehari-hari (edukasi,rekreasi,dan konservasi).

\section{PEMBAHASAN}

"Revitalisasi museum merupakan salah satu kegiatan dalam rangka Gerakan Nasional Cinta Museum, yang bertujuan untuk meningkatkan apresiasi masyarakat terhadap museum, meningkatkan profesionalisme dalam pengelolaan museum dan pelayanan pengunjung, dan menjadikan museum sebagai pranata sosial yang mampu membangkitkan kebanggaan dan memperkukuh jati diri bangsa," Intan Mardiana menjelaskan, revitalisasi museum 
adalah kesadaran untuk menempatkan kembali arti penting museum secara proporsional dan kontekstual. Dengan demikian, museum diharapkan dapat mengubah citra dan wajah museum Indonesia menjadi lebih menarik dan prima sehingga dapat meningkatkan jumlah kunjungan wisatawan. "Diperlukan gerakan bersama untuk penguatan pemahaman, apresiasi, dan kepedulian terhadap identitas dan perkembangan budaya bangsa yang harus terbangun pada tataran semua komponen masyarakat Indonesia,"

Museum adalah lembaga tetap yang nirlaba (tidak mencari keuntungan) yang melayani masyarakat dan perkembangannya, terbuka untuk umum, yang mengumpulkan, memelihara, meneliti, mengkomunikasikan, dan memamerkan. Untuk tujuan studi, edukasi, dan kesenangan, tinggalan tangible dan intangible manusia dan lingkungannya. (ICOM Code of Ethics for Museums, 2006: 14).

Museum, berdasarkan definisi yang diberikan International Council of Museums disingkat ICOM, adalah institusi permanen, nirlaba, melayani kebutuhan publik, dengan sifat terbuka, dengan cara melakukan usaha pengoleksian, mengkonservasi, meriset, mengkomunikasikan, dan memamerkan benda nyata kepada masyarakat untuk kebutuhan studi, pendidikan, dan kesenangan. Karena itu ia bisa menjadi bahan studi oleh kalangan akademis, dokumentasi kekhasan masyarakat tertentu, ataupun dokumentasi dan pemikiran imajinatif di masa depan.

Pada saat masyarakat mulai kehilangan orientasi akar budaya atau jati dirinya, maka museum dapat memberi inspirasi tentang hal-hal penting dari masa lalu yang harus diketahui untuk menuju ke masa depan. Oleh karena itu, untuk menempatkan museum pada posisi sebenarnya yang strategis, diperlukan gerakan bersama untuk penguatan, pemahaman, apresiasi dan kepedulian akan identitas dan perkembangan budaya bangsa yang harus terbangun pada semua tataran komponen masyarakat bangsa Indonesia, baik dalam skala lokal, regional maupun nasional. Gerakan bersama tersebut dinamakan Gerakan Nasional Cinta Museum (GNCM). Tahun Kunjung Museum 2010 merupakan momentum awal memulai Gerakan Nasional Cinta Museum (GNCM) yang dilaksanakan selama 5 tahun (2010-2014).

Salah satu kegiatan dalam program GNCM adalah revitalisasi museum untuk mewujudkan museum Indonesia yang dinamis dan berdaya guna sesuai dengan standar ideal pengelolaan dan pemanfaatan museum. Dengan program GNCM, tahun 2014 akan terwujud museum Indonesia yang menarik dan informatif serta mampu memenuhi kebutuhan masyarakat. Adapun latar belakang dan tujuan di adakannya program ini oleh Kementrian Kebudayaan dan Pariwisata adalah:

a. Untuk melestarikan Karya, Budaya dan Peninggalan sejarah bangsa.

b. Sebagai magnet untuk mendongkrak sektor wisata lain.

c. Meningkatkan pengetahuan, kesadaran dan apresiasi masyarakat/wisatawan akan kekayaan wisata Indonesia dan warisan budaya bangsa.

d. Meningkatkan jumlah pengunjung museum yang terus menurun dari tahun ke tahun

e. Terwujudnya museum sebagai kebanggaan publik.

Museum juga merupakan faktor penting dalam menarik wisatawan ke suatu daerah sehingga dapat berperan dalam membantu ekonomi lokal dalam hal penyediaan perdagangan yang melintas serta membuka lapangan kerja.

a. Media pembinaan pendidikan kesenian dan ilmu pengetahuan

b. Suaka alam dan suaka budaya

c. Cermin sejarah manusia, alam, dan kebudayaan.

d. Sarana untuk bertakwa dan bersyukur kepada Tuhan Yang Maha Esa.

e. Sarana dalam pengembangan budaya dan peradaban manusia. Dengan kata lain, 
museum tidak hanya bergerak di sektor budaya, melainkan juga dapat bergerak di sektor ekonomi, politik, sosial, dan lain-lain.

f. Wahana yang memiliki peran strategis terhadap penguatan identitas masyarakat.

Revitalisasi Museum adalah program yang pada saat itu diusung oleh pemerintah melalui Kementerian Kebudayaan dan Pariwisata yang dilaksanakan oleh Direktorat Jenderal Sejarah dan Purbakala dengan jajaran di bawahnya, yaitu Direktorat Museum, yang bertugas dan berfungsi melakukan pembinaan teknis museum di Indonesia. Revitalisasi museum dimaknai sebagai upaya meningkatkan kualitas museum untuk melayani masyarakat sesuai dengan fungsi museum.

Revitalisasi Museum merupakan upaya untuk meningkatkan kualitas museum dalam melayani masyarakat sesuai dengan fungsi museum. Pada pelaksanaannya, revitalisasi ini mengacu pada tiga pilar kebijakan permuseuman, yaitu mencerdaskan bangsa, memperkuat kepribadian bangsa, ketahanan nasional dan wawasan nusantara.

Revitalisasi Museum terdiri atas enam aspek, yaitu fisik, manajemen, jejaring, program kebijakan, dan pencitraan. Ada enam aspek yang akan direvitalisasi dari museum di Indonesia, yaitu:

a. Aspek Fisik: Tampilan museum menjadi lebih menarik.

b. Aspek Manajemen: Profesionalisme dalam pengelolaan museum dan pelayanan pengunjung meningkat.

c. Aspek Program: Program yang inovatif dan kreatif berkembang.

d. Aspek Kebijakan: Menetapkan kebijakan pengelolaan museum.

e. Aspek Pencitraan: Meningkatkan pencitraan museum.

f. Aspek Jaringan: Mewujudkan dan memperkuat jejaring museum dan komunitas.

Konsep tata ruang bangunan museum sudah selayaknya ditata kembali sesuai dengan paradigma museum yang baru dan rencana program revitalisasi museum ke depan, sbb:

a. Bangunan mampu memberi citra sebagai museum.

b. Bangunan diharapkan menjadi lebih 'terbuka' dan ramah terhadap lingkungan sekitar

c. Bangunan mempunyai orientasi 'keluar' dan 'mengundang' publik.

Ruang di dalam bangunan mempunyai beberapa variabel, dalam konteks ruang di dalam museum yang harus diperhatikan adalah fungsi dan bentuk ruang. Ruang pameran sebagai bagian dari sebuah museum sesungguhnya mengacu pada fungsi dan bentuk bangunan museum itu sendiri.

Dalam hal ini ada 4 fungsi dan bentuk bangunan museum, yaitu; Bangunan yang memang dari awal dirancang sebagai museum; Bangunan biasa atau umum yang dijadikan sebagai museum; Bangunan yang mempunyai latar belakang sejarah dengan menjadikan bangunan itu sebagai museum yang mempunyai hubungan peristiwa atau dengan tokoh tertentu; dan Bangunan cagar budaya sebagai museum. Sedangkan penataan-rehabilitasi fisik bangunan dilakukan dengan prioritas pada ruang-ruang publik, ruang pameran dan penyimpanan, penataan yang dilakukan sebagai berikut:

\section{Penataan eksterior-tata ruang luar museum.}

Konsep penataan eksterior harus terakomodasi dengan jelas dalam gambar rencana tapak (siteplan). Penataan diutamakan pada halaman muka museum yang berorientasi kepentingan publik, dan taman yang berhubungan dengan ruang-ruang publik yang berada di dalam bangunan. Semua ruang publik pada eksterior museum harus diberi penanda (signage) dengan standar yang berlaku, harus jelas terbaca, dan mudah terlihat. Penataan eksterior-ruang luar harus menekankan kenyamanan dan keamanan publik, seperti; a) 
pintu masuk-keluar bangunan; b) taman atau ruang sign-board museum; c) taman parkir kendaraan; d) tersedianya ruang pedestrian bagi pejalan kaki dengan petunjuk masukkeluar bangunan yang jelas.

\section{Penataan interior ruang publik}

Program revitalisasi fisik museum memang memberi prioritas utama kepada penataan kembali interior museum, khususnya Penataan Interior Ruang Pameran Tetap yang merupakan zona satu dari 4 zona di dalam museum, yaitu zona koleksi-publik. Ruang-ruang publik yang menjadi sasaran berikut dalam penataan interior museum masuk dalam zona non koleksi-publik yaitu ruang lobi museum, ruang informasi, ruang tiket, toilet, ruang multi media, dan ruang fasilitas penunjang yang diperlukan. Konsep penataan interior pada ruang publik boleh berbeda dan lebih lunak persyaratannya dibandingkan dengan ruang pameran dan penyimpanan, meskipun tetap memperhatikan unsur 'safety' pengunjung atau publik. Setelah target penataan interior ruang pameran tetap tercapai dan interior ruang publik, target selanjutnya adalah ruang penyimpanan (storage), diikuti ruang pengenalan (introduction area), ruang laboratorium, dan bengkel kerja preparasi.

\section{TAHAPAN REVITALISASI}

1. Sebelum Revitalisasi
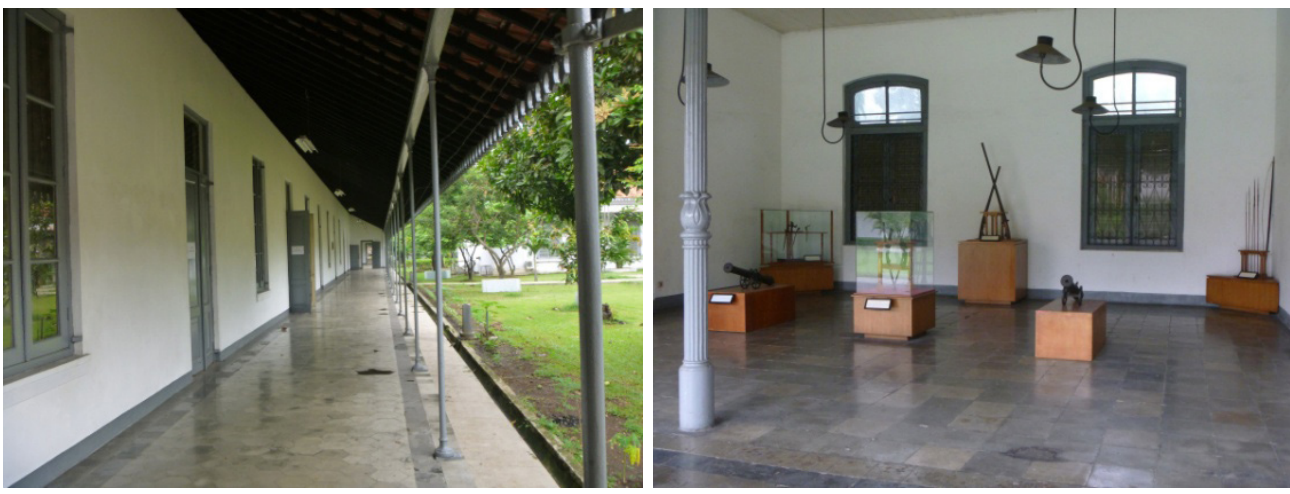

Gambar 1. Selasar dan Ruang Pamer Sumber: Data Pribadi

2. Pelaksanaan Revitalisasi
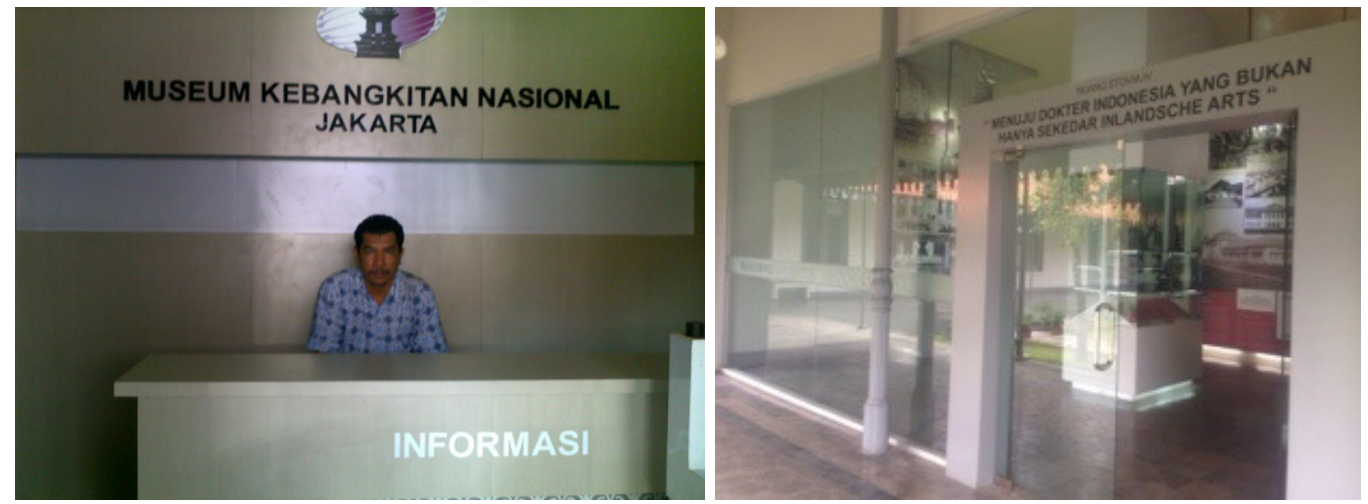

Gambar 2. Ruang informasi dan Ruang Pamer Sumber: Data Pribadi 


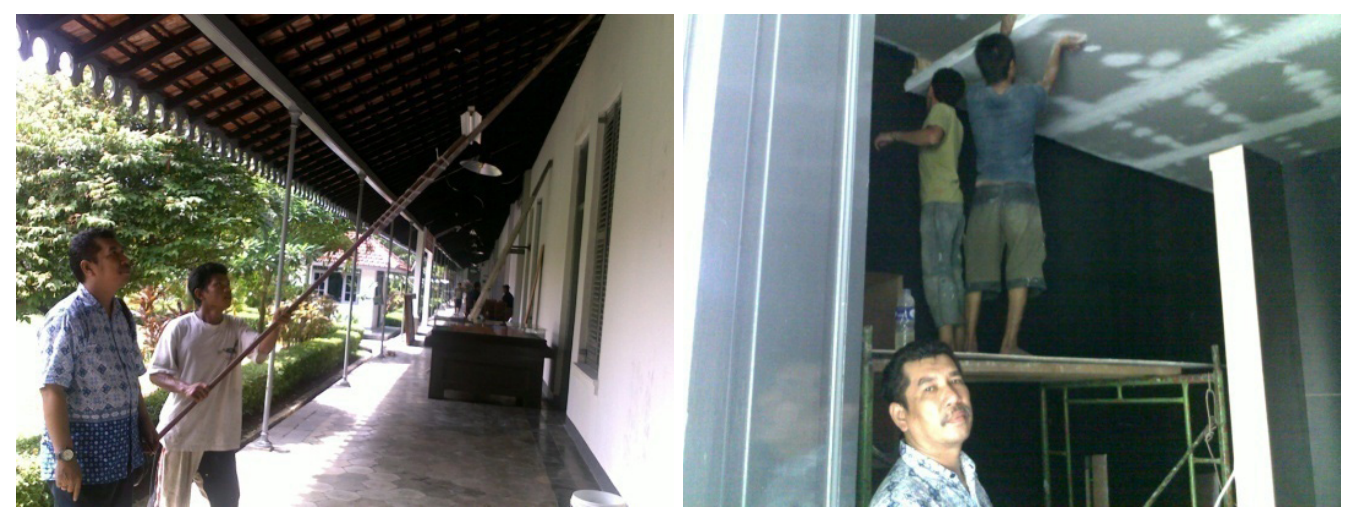

Gambar 3. Selasar dan Ruang Audio Visual Sumber: Data Pribadi

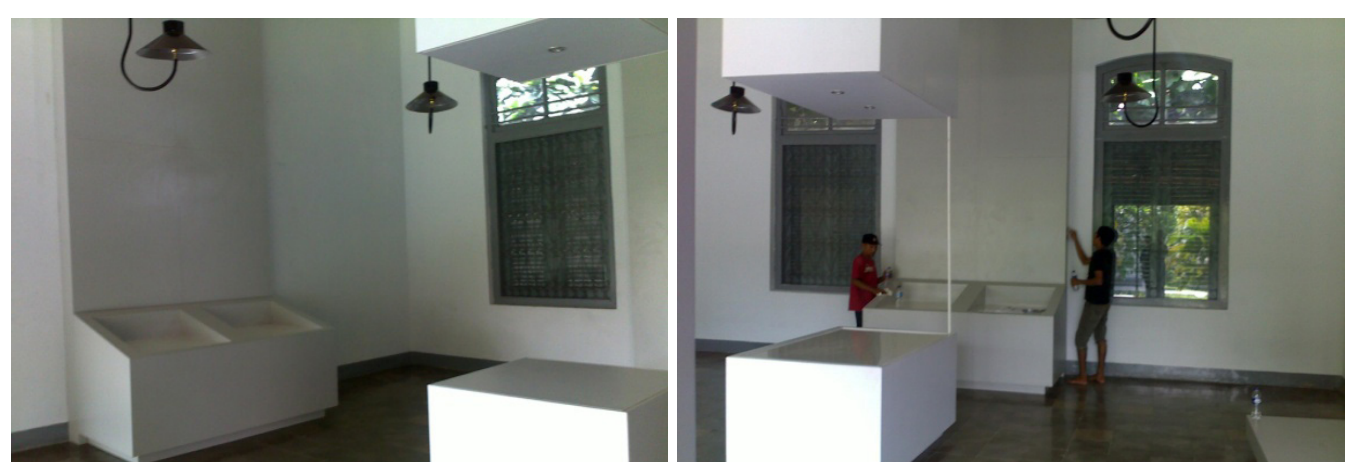

Gambar 4. Ruang pamer

Sumber: Data Pribadi

\section{Setelah Revitalisasi}
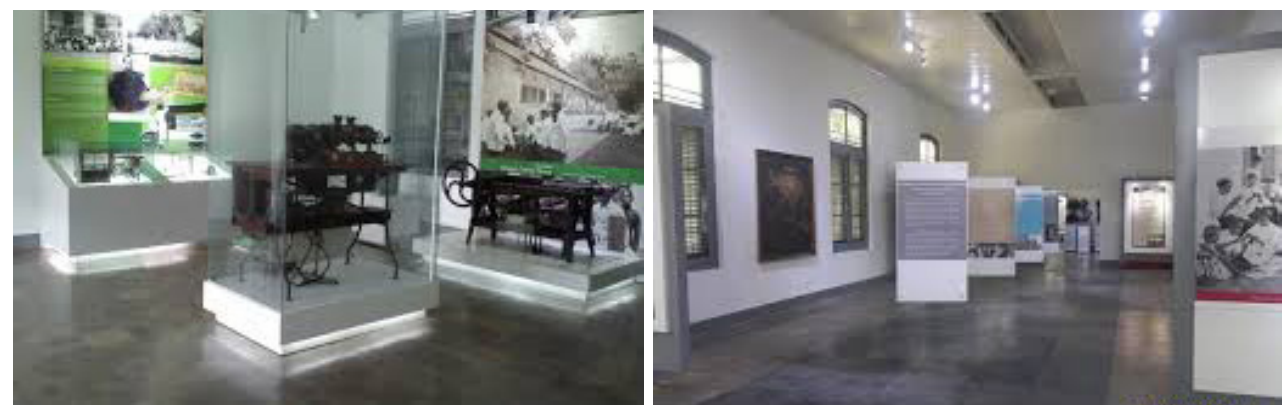

Gambar 5. Ruang pamer

Sumber: Data Pribadi

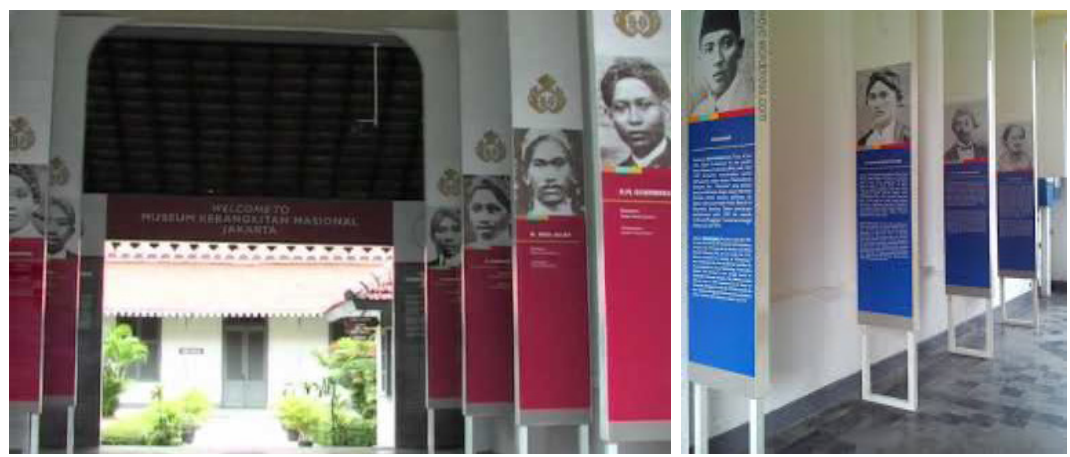

Gambar 6. Ruang Selasar dan Ruang Perantara Sumber: Data Pribadi 


\section{PENUTUP}

Perencanaan desain interior yang baik merupakan cara yang efektif untuk berkomunikasi dengan pengunjung, selalu diawali dengan sebuah gagasan besar tentang apa yang ingin disampaikan kepada masyarakat luas. Gagasan desain kemudian diwujudkan dengan menyajikan ruang baru dengan berbagai koleksi yang dilengkapi teks, gambar, foto, ilustasi dan pendukung lainnya. Perencanaan desain interior merupakan faktor penting untuk menentukan strategi kerja dan tahapan pelaksanaan hingga evaluasi, serta dibutuhkan keterlibatan banyak pihak dan keahlian dan ketrampilan khusus bagi yang terlibat di dalamnya.

\section{DAFTAR PUSTAKA}

Encyclopedia Americana, (1970), New York: Americana Corporation.

Hoed, Benny H, (2008), Semiotik dan Dinamika Sosial Budaya, Depok: Fakultas Ilmu Pengetahuan Budaya (FIB) UI.

Hunter, K, (1988), Heritage Education in the Social Studies. ERIC Digest.

Museografia, (2010), Majalah Ilmu Permuseuman Vol IV no. 5. Jakarta: Direktorat Jendral Sejarah dan Purbakala Kementrian Kebudayaan dan Pariwisata.

Sumaatmadja, N, (2002), Pembelajaran IPS pada tingkat Pendidikan Dasar dan Menengah, Makalah Seminar nasional dan Musda I HISPIPSI Jawa Barat. 